\title{
Wheelchair-Accessible Toilet at Gambir Station
}

\author{
Fermanto Lianto $^{1 *}$ Eddy Supriyatna $^{1}$ William ${ }^{2}$ Fanny Budiyanto ${ }^{2}$
}

\author{
${ }^{1}$ Lecture of Master of Architecture, Universitas Tarumanagara, Jakarta, Indonesia \\ ${ }^{2}$ Student of Master of Architecture, Universitas Tarumanagara, Jakarta, Indonesia \\ *Corresponding author. Email: fermantol@ft.untar.ac.id
}

\begin{abstract}
Many urban public transportation facilities have not yet considered the needs of disabilities. There are at least $10 \%$ of disabilities in developing countries. The lack of fulfillment in public facilities for disabilities will certainly prevent them from making full social life participation. As one of the most extensive urban public transportation facilities in Jakarta, Gambir Station should be able to provide facilities that can be used by everyone without exception. Nevertheless, based on published research, it is known that there are still some facilities at Gambir Station that have not been following the needs of disabilities; one of them is toilet facilities. There needs to be a re-layout and improvement of facilities in the toilets at Gambir Station to become accessible for people with disabilities. The research method used is qualitative phenomenology. Primary data collection was carried out by participated-observation, interviews with Gambir Station management, wheelchair users, conditioned respondents, and facility trials. The data is analyzed using the directed content analysis approach; later, the data will be used to reference toilet layout recommendations that follow the needs of people with disabilities. This recommendation's results are supposed to be applied at Gambir Station and become a reference for other stations in Indonesia.
\end{abstract}

\section{Keywords: Accessible, Disabilities, Gambir Station, Toilet, Wheelchair}

\section{INTRODUCTION}

Many urban public transport facilities throughout the world are designed for non-disabilities people and rarely consider the needs of disabilities [1]. There are at least $10 \%$ of disabilities in developing countries [2], whereas, in Indonesia, there are around $10-15 \%$ of disabilities [3]. However, the existence of disabilities is often overlooked, especially in meeting the needs of their facilities [4]. The lack of fulfillment of public facilities for disabilities in Indonesia will limit freedom of accessibility so that they experience obstacles in making full participation in social life [5].

Even though there are already many legal regulations governing equal rights disabilities, including Indonesian Government Regulation Number 43 of 1998 concerning efforts to improve the social welfare of people with disabilities, Law No. 28 of 2002 concerning buildings, Indonesian Regulation of the Minister of Public Works and Public Housing No. 14/PRT/M/2017 concerning Requirements for Ease of Building Construction, and various other regulations. Nevertheless, this regulation does not appear to be a reference in building public facilities to provide facilities that meet the needs of disabilities. There are still many public facilities in Indonesia that do not meet the needs of disabilities, especially in urban public transportation facilities [6].

As one of the most extensive urban public transport facilities in Jakarta, Gambir Station should be able to provide facilities that everyone can use without exception. However, based on a study entitled "Exploring Gambir Station by Wheelchair" conducted by researchers, it is known that there are still several facilities at Gambir Station that do not yet meet the needs of disabilities [7]. Consequently, as a direction for further thought development, the researcher will provide recommendations for facilities for disabilities at Gambir Station that are focused on the toilet area. The purpose of focusing on the problem is so that the discussion can be more detailed in providing recommendations for disabilities facilities. Researchers also focus on wheelchair users because the problems involving wheelchair users of toilet facilities are more complicated than other types of disabilities.

Recommendations offered in this study are alternative disability toilet layouts and recommended facility sizes to meet the needs of disabilities. The results of this study are supposed to be applied at Gambir Station. They can be a reference for other stations in Indonesia to provide station facilities suitable for the needs of disabilities.

\section{MATERIAL AND METHOD}

\subsection{Wheelchair User's Obstacles}

a. Mobility

Facilities related to mobility function to determine how a person can move from one place to another [8]. Things 
to consider in mobility problems are issues regarding travel routes that can be accessed by wheelchair users, surface slope, differences in surface levels, drainage channels, and texture of road surfaces accessed by wheelchair users [9].

b. Space

Wheelchair users need a greater area of movement when compared to non-disabilities. Therefore, the designers need to consider the more spacious requirements for wheelchair users, circulation access, and the width of the door openings that are accessible for wheelchair users. [10].

c. Posture

The anthropometric characteristics of wheelchair users differ from the anthropometric characteristics of nondisabilities [11]. This problem occurs because people who use wheelchairs for extensive periods will usually cause the upper body to develop more than the lower body, which is underdeveloped and weakens [12].

d. Reach

Wheelchair users have a limited range, one of which is having a lower eye level compared and shorter hand reach than non-disabilities. This problem has a significant influence on the design criteria, so the designer must design a variety of building equipment following the range and visibility for wheelchair users [9].

\section{e. Strength}

Complaints that often occur to wheelchair users are the problem of doors that are difficult or impossible to open because they have heavy spring hinges. Then the door should be designed so that wheelchair users can use the minimum amount of effort to be able to open the door [8].

\subsection{Toilet Requirement}

Every toilet for males and females must have at least one disability toilet or have one disability toilet in separate sections. Disability toilets must be equipped with signs/symbols of "Disability" with the embossed printing system on the outside and have enough space to enter and exit wheelchair users with a minimum of $152.5 \times 227.5 \mathrm{~cm}$ [13]. The height of the closet seat is around $45-50 \mathrm{~cm}$. Toilets must be equipped with a handrail; the handle is recommended to have a right-angled shape pointing up to help the movement of wheelchair users [14]. The minimum opening width of the door is $90 \mathrm{~cm}$ and opens outwards. The toilet must be equipped with an emergency light button on the toilet inside to sign if something dangerous is happening. The minimum Washbasin size is $45 \mathrm{x} 60 \mathrm{~cm}$, with a height of $75 \mathrm{~cm}$ for wheelchair users-free space under the Washbasin at least $60 \mathrm{~cm}$ from the Washbasin's edge (Figure 1).

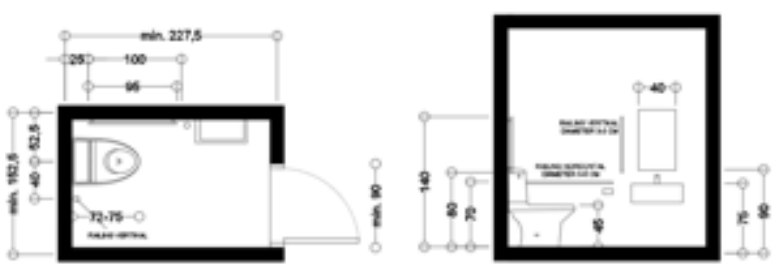

Figure 1. Disability toilet configuration

\section{METHODS}

This qualitative research uses a phenomenological approach as a study that aims to explore individuals' life experiences and find out how individual experiences are related to the phenomenon [15]. Data collection methods were carried out with participated-observation, semi-structured interviews of the head of Gambir Station's customer service, prospective passengers (wheelchair users) and conditioned respondents, and trials of facilities. The data is analyzed using the directed content analysis approach by comparing sources with related theories. The results of this study are toilet recommendations that suit the needs of wheelchair users.

\section{FINDING AND DISCUSSION}

Gambir Station is one of the largest stations located at Jalan Medan Merdeka Timur No.1, Central Jakarta, DKI Jakarta. Gambir Station has three toilet areas located on the ground floor. Toilet area A is outside the boarding gate (marked in red), toilet area B is the toilet that is after the boarding gate (marked in blue), and toilet area $\mathrm{C}$ is near the north exit (marked in green). To find out the position of the toilet in Gambir Station, see figure 2.

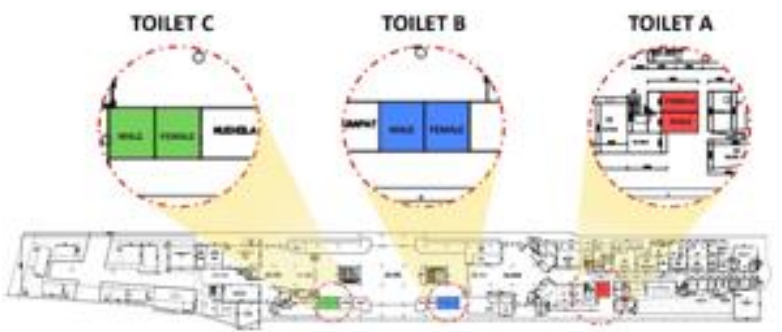

Figure 2. Toilet location at Gambir Station

\subsection{Toilet A}

There is no disabled toilet in toilet A (Figure 3-4), so based on the results of observations and interviews conducted, researchers know that respondents have difficulty accessing the toilet and need help from a third party to access it. The average toilet space in toilet A is $120 \times 148 \mathrm{~cm}$ (male) and $105 \times 148 \mathrm{~cm}$ (female), this area is certainly not ideal for wheelchair users. 


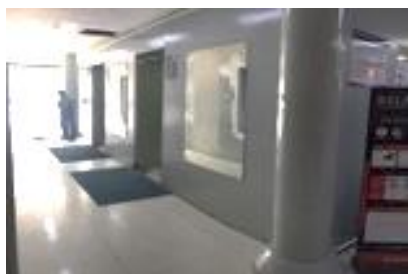

Figure 3. Outside photo of the toilet A

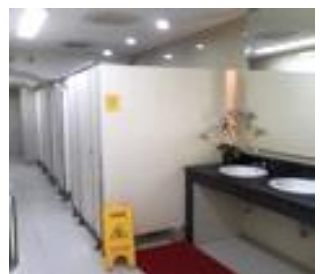

Figure 4. Interior condition of toilet A
Accordingly, researchers provide recommendations for the layout of toilet $A$ as in figure 6 . This layout recommendation aims to make the toilet have a disabled toilet facility. However, researchers tried not to make any changes to the existing layout of toilet A (Figure 5), especially to the toilet plumbing system. Researchers recommend a disability toilet room of $245 \times 180 \mathrm{~cm}$, where the toilet and Washbasin positions are in a parallel position to facilitate wheelchair users in their activities on the toilet (Figure 6).

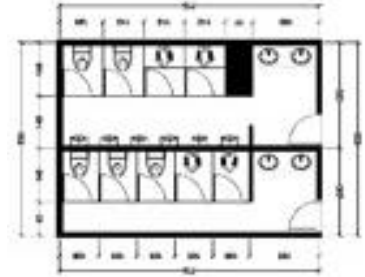

Figure 5. Existing layout toilet A

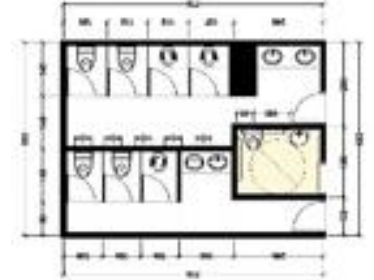

Figure 6. Recommendation layout toilet A
Researchers recommend toilets to use automatic sliding doors with sensor buttons on the outside (Figure 7) and inside the toilet door to facilitate circulation in and out for wheelchair users. The toilet also has an auto-flush system with a motion sensor and adjustable handrail (can be adjusted as needed and moved vertically by 90 degrees). The user can access all toilet settings (position settings for handrail, jet-spray, and emergency light buttons) through the right handle. In the Washbasin area, the researchers recommend a $75 \mathrm{~cm}$ height with a legroom of $65 \mathrm{~cm}$. This Washbasin has an automatic water and soap faucet system. This aims to minimize activities that make it difficult for wheelchair users (such as opening water taps and pressing soap). The Washbasin has a mirror with a height of $85 \mathrm{~cm}$ (bottom) and $150 \mathrm{~cm}$ (top). The mirror position is tilted by 5 degrees to make it easier for wheelchair users to reflect (Figure 8).

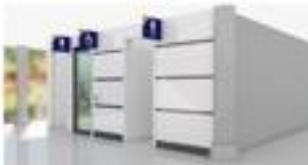

Figure 7. exterior toilet $\mathrm{A}$
Recommendation

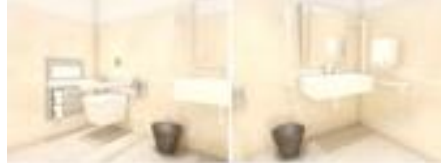

Figure 8. Recommendation interior the toilet $\mathrm{A}$

\subsection{Toilet $B$}

Based on research conducted, researchers found that Toilet B already has a disability toilet, where there was one disability toilet room in the male's room and one disability toilet room for the female's room (Figure 9). In this toilet, researchers observed in detail the male's disability toilet. Based on these observations, the researchers found a disability symbol on the outside of the toilet and the front of the toilet door. The disability toilet area is $160 \times 160 \mathrm{~cm}$. However, there is a floor elevation in the closet area, which causes the wheelchair not to enter fully into the toilet room because the elevation blocks it (Figure 10-11). Another problem is the toilet closet, which is too low, $42 \mathrm{~cm}$, while the standard toilet closet for wheelchair users is $45-50 \mathrm{~cm}$. This toilet has facilitated a handrail with a height of $110 \mathrm{~cm}$, while the standard height of the handrail is $70-75 \mathrm{~cm}$. The tissue holder in this toilet is also placed too high, which is $118 \mathrm{~cm}$, whereas the tissue holder's standard height for the disabled is $65 \mathrm{~cm}$. The emergency light button is also not provided on the toilet.

Table 1. Male disability toilet B

\begin{tabular}{lllll}
\hline No. & Facility & Criteria & Fulfilled & Information \\
\hline 1 & Toilet & Closet Height: $45-50 \mathrm{~cm}$ & Not Fulfilled & Height of the toilet seat $42 \mathrm{~cm}$ \\
& Handrail Height: $70-75 \mathrm{~cm}$ & Not Fulfilled & Height of handrail $110 \mathrm{~cm}$ \\
& Tissue Box Height: $65 \mathrm{~cm}$ & Not Fulfilled & Height of tissue box $118 \mathrm{~cm}$ \\
& Toilet Dimension: $152.5 \mathrm{x} 228,5 \mathrm{~cm}$ & Not Fulfilled & Area $160 \mathrm{x} 160 \mathrm{~cm}$ \\
& Floor Material: not slippery & Fulfilled & Using mate ceramics \\
& Disability signage's & Fulfilled & Disability signage's at the outside of the toilet \\
& Emergency light button & Not Fulfilled & Do not have \\
& The toilet door opens to the outside & Fulfilled & The toilet door opens to the outside \\
& Washbasin & Not Fulfilled & Width of Washbasin $50 \mathrm{~cm}$ \\
& Minimal width: $80 \mathrm{~cm}$ & Not Fulfilled & Height of Washbasin $75 \mathrm{~cm}$ \\
& Maximum height: $85 \mathrm{~cm}$ & Fulfilled & Not sharp edges \\
& Not sharp edges & Fulfilled & Mounted on the wall \\
& Mounted on the wall & Not Fulfilled & Using the rotary system \\
& The faucet uses a lift system & &
\end{tabular}




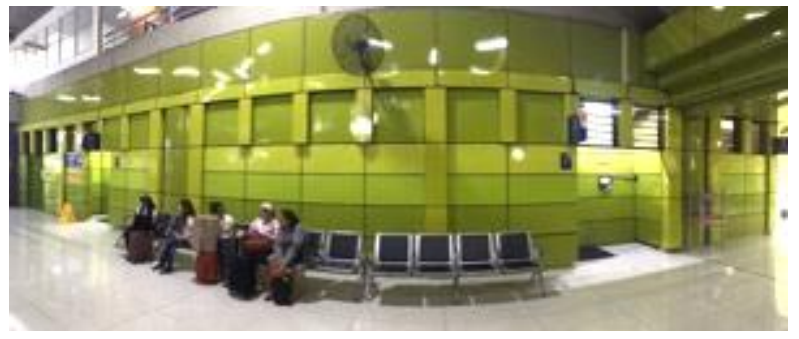

Figure 9. Existing photo of toilet B [7]
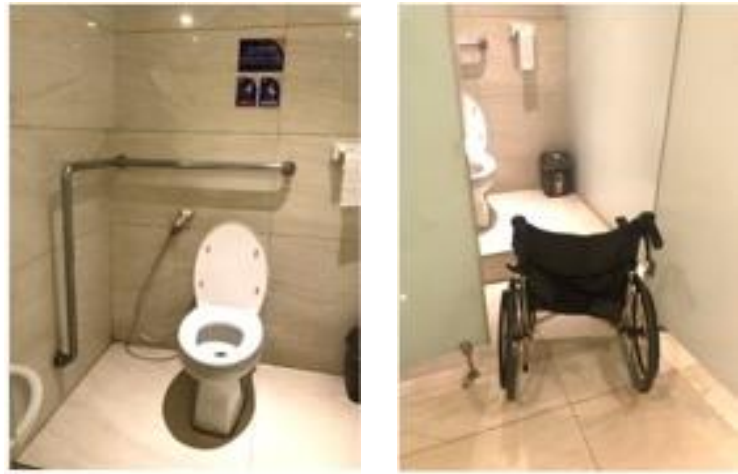

Figure 10. Interior of male disability toilet B [7]

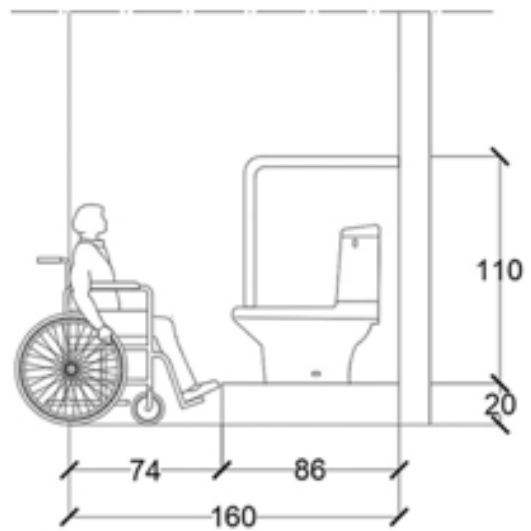

Figure 11. Illustration of male disability toilet B [7]

According to the analysis, the researcher recommends that disabled toilets are not inside male or female toilets. Toilets are outside and accessible to men and women with disabilities. The researcher provides recommendations for the layout of disability toilets, as in Figure 13. In the layout recommendation, the researcher tries to recommend a room for disabled toilets with minimal changes to the layout. The management does not need to make any changes, especially to the plumbing system. The interior recommendations, specifications, and dimensions of toilet B (Figure 13-14) are the same as toilet $\mathrm{A}$.

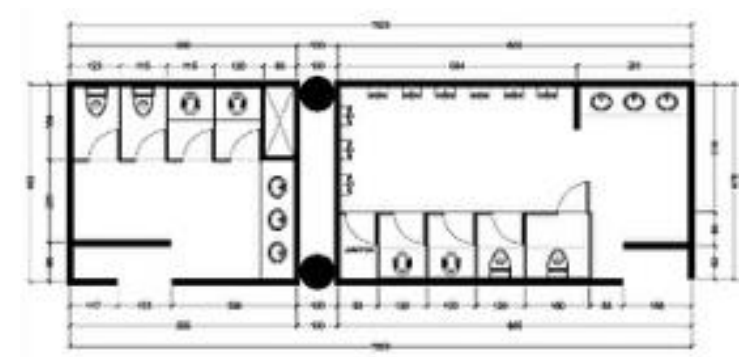

Figure 12. Existing layout toilet B

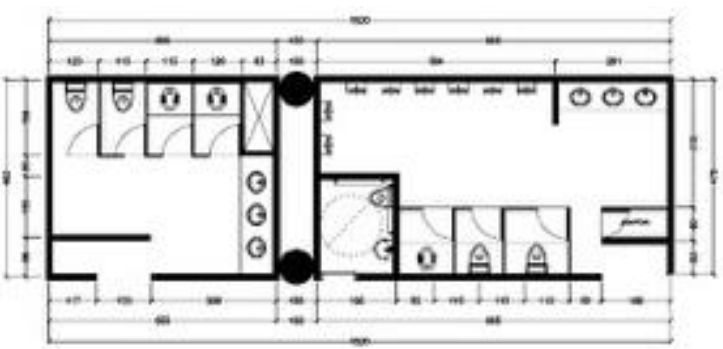

Figure 13. Recommendation layout toilet $B$

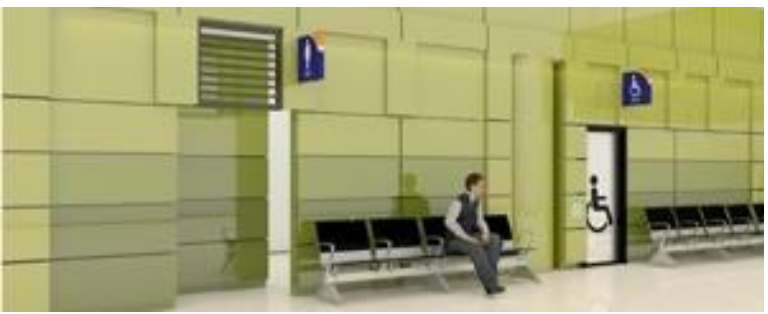

Figure 14. Recommendation exterior toilet $B$

\subsection{Toilet $C$}

Toilet $\mathrm{C}$ also already has a disability toilet. There are one male's disability toilet room and two female's disability toilet rooms (Figure 16). In this toilet, researchers observed in detail the men's disability toilet (Figure 17). Based on observations made on male toilet C (Figure 18), it is known that the disability toilet already has a disability symbol on the outside and front of the toilet door. There is a partition (barrier) at the front of the toilet. This partition (barrier) serves to block the direct view of the toilet. However, the partition (barrier) makes it difficult for wheelchair users to access the toilet because they have to manoeuver in a narrow area. This disability toilet room has a room area of $102 \times 150 \mathrm{~cm}$, where the minimum standard is $152.5 \times 227.5$ $\mathrm{cm}$. This toilet door opens inward, causing wheelchair users to have difficulty closing the door. This toilet-handrail height of $110 \mathrm{~cm}$ and $114 \mathrm{~cm}$ of the tissue box, which is not suitable. The Washbasin provided is not ideal, where the width of the Washbasin is only $50 \mathrm{~cm}$ with a height of 88 $\mathrm{cm}$, while ideally, the width is $85 \mathrm{~cm}$, and the maximum height is $85 \mathrm{~cm}$. Another problem is the use of a rotary system on a water faucet that should use a lift or tap system. 
Table 2. Male disability toilet $\mathrm{C}$

\begin{tabular}{lllll}
\hline No. & Facility & Criteria & Fulfilled & Information \\
\hline 1 & Toilet & Closet Height: $45-50 \mathrm{~cm}$ & Fulfilled & Height of the toilet seat $48 \mathrm{~cm}$ \\
& Handrail Height: $70-75 \mathrm{~cm}$ & Not Fulfilled & Height of handrail $110 \mathrm{~cm}$ \\
& Tissue Box Height: $65 \mathrm{~cm}$ & Not Fulfilled & Height of tissue box $114 \mathrm{~cm}$ \\
& Toilet Dimension: $152.5 \times 228,5$ & Not Fulfilled & Area $102 \times 150 \mathrm{~cm}$ \\
& cm & Fulfilled & Using mate ceramics \\
& Floor Material: not slippery & Fulfilled & $\begin{array}{l}\text { Disability signage's at the outside of the } \\
\text { toilet }\end{array}$ \\
& Disability signage's & Not Fulfilled & Do not have \\
& Emergency light button & Not Fulfilled & The toilet door opens to the inside \\
& The toilet door opens to the & Not Fulfilled & Width of Washbasin $50 \mathrm{~cm}$ \\
& outside & Not Fulfilled & Height of Washbasin $75 \mathrm{~cm}$ \\
& Minimal width: $80 \mathrm{~cm}$ & Fulfilled & Not sharp edges \\
& Maximum height: $85 \mathrm{~cm}$ & Fulfilled & Mounted on the wall \\
& Not sharp edges & Not Fulfilled & Using the rotary system \\
\hline & Mounted on the wall & & \\
& The faucet uses a lift system & &
\end{tabular}

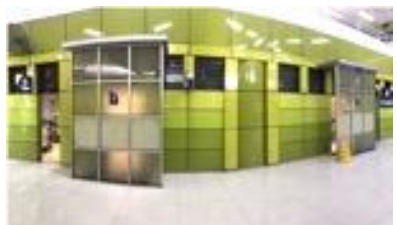

Figure 15. Outdoor of toilet C
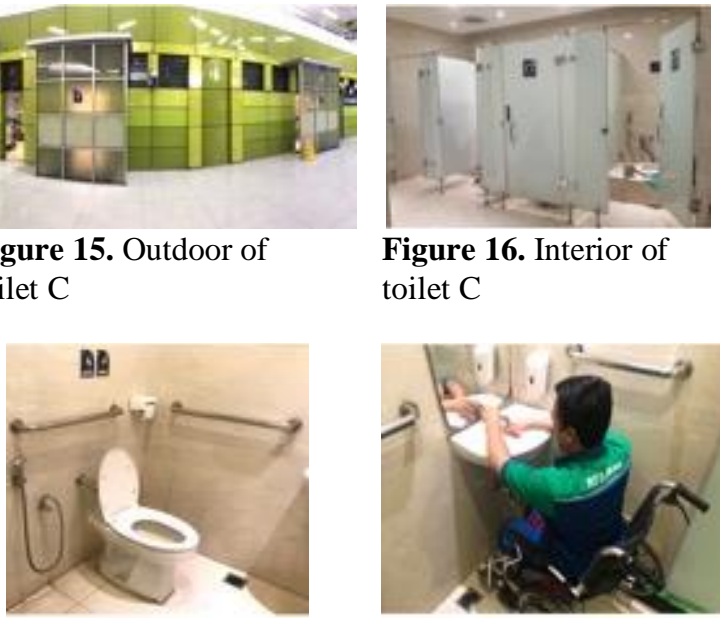

Figure 16. Interior of toilet C

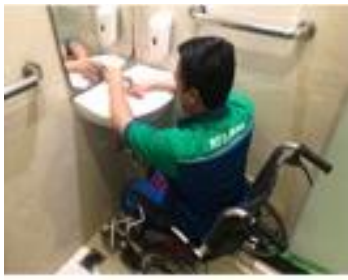

Figure 17. Interior of male disability toilet C [7]

According to the analysis, the researchers recommend the disability toilet layout as in figure 20. The layout recommendation is the same as the recommendation on toilet $\mathrm{B}$, which is to provide disabled toilets outside of male and female toilets by considering efficiency for wheelchair users (Figure 18). Researchers give the recommendations for minimal changes to the existing layout (Figure 19) so that the management does not need to make changes, especially in the plumbing system. The interior recommendations, specifications, and dimensions of toilet C (Figure 20) are the same as toilet B.

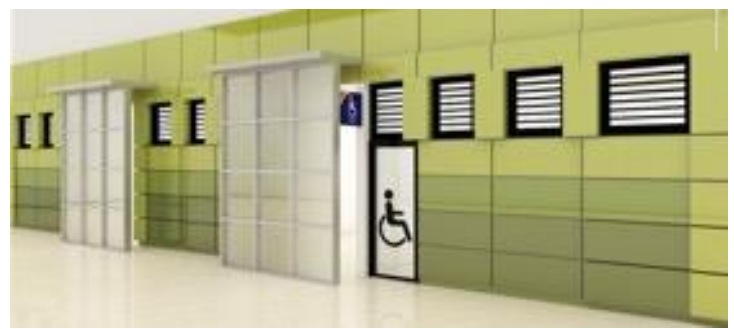

Figure 18. Recommended Exterior of Toilet $\mathrm{C}$

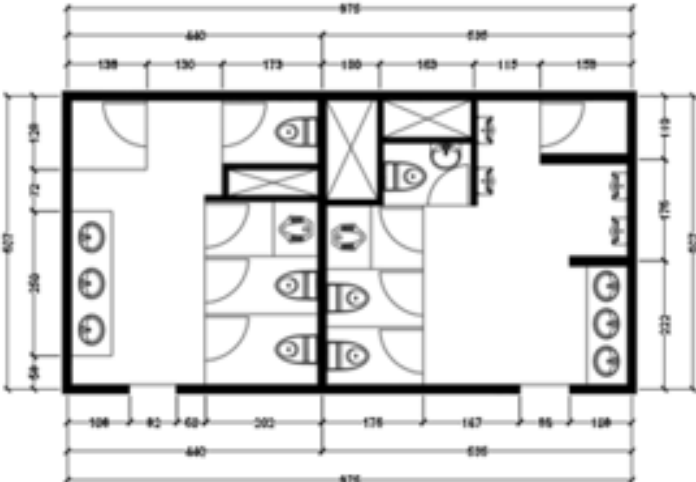

Figure 19. Existing Layout of Toilet $\mathrm{C}$

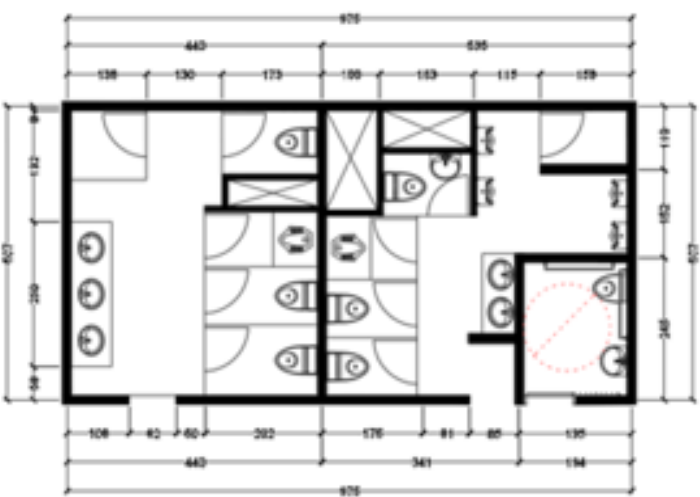

Figure 20. Recommended Layout of Toilet C

\section{CONCLUSIONS}

According to the observations and analysis above, it was concluded that Gambir Station already has disability toilet facilities, but the condition of the toilet is not yet by the needs of disabilities, especially wheelchair users. Consequently, disability toilet facilities at Gambir Station need to be improved or added by considering the ease of 
mobility, space, posture, reach, and strength of wheelchair users. In this study, researchers recommend a disabled toilet layout with minimal changes to the existing layout. The management does not need to make any changes, especially to the plumbing system, as shown in the design recommendation. Researchers expect that the disability toilet layout recommendations will make it easier for people with disabilities to access the toilet independently.

\section{ACKNOWLEDGMENT}

We gratefully thank Kemenristekdikti for supporting this research through a thesis grant. We thank Mr. Tri Eko Yuwono as the Human Resources Division of DAOP 1 Jakarta and Mr. Iwan Junaidi as Head of Gambir Station Customer Service for their support in the data collection and permission to survey at Gambir Station.

\section{REFERENCES}

[1] P. Roberts and J. Babinard, "Transport Strategy to Improve Accessibility in Developing Countries," World Bank Group, Washington DC, 2004.

[2] W. H. Organization, "Summary World Report on Disability,” WHO Publications, Geneva, 2011.

[3] S. M. Adioetomo, D. Mont and Irwanto, "Person with Disabilities in Indonesia: Empirical Facts and Implications for Social Protection Policies," Lembaga Demografi Fakultas Ekonomi Universitas Indonesia, Jakarta, 2014.

[4] T. Savill, J. Stone, C. Venter, and D. Maunder, "Improving access to transport in developing countries," Municipal Engineer, vol. 156, no. 2, pp. 149-153, 2003.

[5] M. Damayanti and F. Sabiq, "Implementation of Public Facilities and Disability Treatments: A Comparison Between Indonesia and Malaysia," Advances in Social Science, Education and Humanities Research, vol. 153, no. 1, pp. 11-15, 2017.

[6] L. Cameron and D. C. Suarez, "Disability in Indonesia: What can we learn from the data?," Monash University, Melbourne, 2017.
[7] William, E. Supriyatna and F. Lianto, "Exploring Gambir Station by Wheelchair," in Tarumanagara International Conference on The Applications of Social Science \& Humanities (TICASH 2019), Jakarta, 2019.

[8] S. Goldsmith, Designing for Disabled, New York: Routledge, 2011.

[9] N. N. Zhe and K. M. Christensen, "Access to urban transportation system for individuals with disabilities," IATSS Research, vol. 41, no. 2, pp. 66-73, 2017.

[10] H. Wennberg, C. Hydén and A. Ståhl, "Barrierfree outdoor environments: Older peoples' perceptions before and after implementation of legislative directives," Transport Policy, vol. 7, no. 6, pp. 464-474, 2010.

[11] K. Lucero-Duarte, E. d. 1. Vega-Bustillos, F. López-Millán, and S. Soto-Félix, "Anthropometric data of adult wheelchair users for Mexican population," in IEA 2012: 18th World Congress on Ergonomics - Designing a sustainable future, Sonora, 2012.

[12] A. A. Dingley, B. Burkett and D. B. Pyne, "Relationships Between Propulsion and Anthropometry in Paralympic Swimmers," International Journal of sports physiology and performance, vol. 10, no. 8, p. 978-985, 2015.

[13] J. Tamba, "Exploring The Accessibility and Facility in Railway Station Used by Persons with Disabilities: An Experience From Kebayoran Railway Station, Jakarta," Indonesian Journal of Disability Studies (IJDS), vol. 5, no. 1, pp. 37-46, 2018.

[14] R. L. Mace, R. J. Pace, L. C. Young, and K. Olander, A Planning Guide for Making Temporary Events Accessible to People With Disabilities, Washington: ADA National Network, 2015.

[15] J. W. Cresswell, Penelitian Kualitatif \& Desain Riset: Memilih di Antara Lima Pendekatan, Yogyakarta: Pustaka Pelajar, 2015. 